Campos Neutrais - Revista Latino-Americana de Relações Internacionais Vol. 1, No 2, p. 53-72, Maio - Agosto de 2019

\title{
A transposição das águas do Rio São Francisco na resposta à seca do Nordeste brasileiro. Cronologia da transformação da ideia em obra
}

José Gomes Ferreira ${ }^{1}$

Resumo: O artigo sintetiza o histórico do Projeto de Integração do Rio São Francisco com Bacias Hidrográficas do Nordeste Setentrional brasileiro, desde a primeira vez que foi apresentado em 1818 até à inauguração da primeira fase da obra com a chegada da água aos estados de Pernambuco e Paraíba. Tem como objetivo debater as várias dimensões do tema colocando em pauta diferentes posicionamentos. Para tal, procede à coleta e análise de documentos e notícias da mídia, de entrevistas, questionários e observação de campo. Os primeiros resultados mostram que a obra tem sido encarada como a principal saída no combate à seca e como infraestrutura capaz de fomentar o desenvolvimento da região. Ainda assim, o projeto motiva discussão quanto aos fins a que se destina, à segregação de comunidades, aos prazos de conclusão, à transparência dos processos e sua adequação à resposta às mudanças climáticas.

Palavras-chave: semiárido. Rio São Francisco. Transposição.

\section{Water transfer from São Francisco River as a solution to the brazilian Northeast drought. Chronology of the transformation of the idea into action}

\begin{abstract}
The paper summarizes the history of the São Francisco River Water Transfer Project to the Northeast's Brazil Hydrographic Basins, since the first time it was presented in 1818 until the inauguration of the first phase of the infrastructure with the arrival of water to the states of Pernambuco and Paraiba. It aims to discuss the various dimensions of the theme considering different positions. For this purpose we collected and analyzed archive documents and news from the media, conducted interviews, applied questionnaires and did field observation. The first results show that the water transfer infrastructure has been seen historically as the main solution to fight Northeast's drought and with a large potential to bring development to the region. Nevertheless, the project motivates discussion about its purpose, segregation of communities, and completion deadlines, transparency and their
\end{abstract}


Campos Neutrais - Revista Latino-Americana de Relações Internacionais

Vol. 1, $\mathrm{N}^{\mathrm{O}}$ 2, p. 53-72, Maio - Agosto de 2019

adequacy to the response to climate change.

Keywords: semiarid. São Francisco River. Water transfer.

\section{Introdução}

A água é cada vez mais um recurso escasso e finito, principal elemento da vida e condição vital para a reprodução material dos organismos. Um dos elementos da natureza com maior presença simbólica e patrimonial, e campo frequente de lutas, privações e evocações, é simultaneamente motivo de conflito e consenso. É igualmente importante na definição da ocupação do território e na dinâmica das relações sociais, no que adquire características que superam o líquido que sai da torneira. É líquido e ativo social na forma como atravessa o nosso quotidiano e intercepta as relações entre cidadãos, consumidores, estado e agentes econômicos (SCHMIDT \& PRISTA, 2010; ARROJO, 2010). A sua função vai para além do abastecimento aos cidadãos e das atividades produtivas, exerce funções ecológicas, presta serviços ambientais e condiciona valores sociais e práticas cotidianas. A sua conceituação é pois cada vez mais ampla e marcada pela questão da escassez e da distribuição desigual, assim como pelas demandas das atividades econômicas, pelas tecnologias hidráulicas, pelo papel diferentes atores sociais e estruturação dos processos de governança (FERREIRA, 2019).

A partir da década de 1960 surgem as primeiras preocupações globais com a água e com o meio ambiente, o que alterou o seu entendimento, colocando em debate a priorização de usos, a degradação dos ecossistemas e as desigualdades sociais e geográficas daí resultantes. O tema ganha igualmente visibilidade com o debate sobre a governança e necessidade de uma nova cultura da água num contexto de mudança climática, agravado pelo crescimento populacional mundial e por dificuldades na concretização de soluções para o saneamento básico em várias geografias.

Historicamente, a escassez está na origem de grandes empreendimentos hidráulicos, para armazenamento e transferência de grandes quantidades de água de bacias excedentárias para bacias deficitárias, tendência que se baseou no mito da prosperidade hídrica e na possibilidade de disponibilizar água através do investimento em grandes infraestruturas hidráulicas. Em vários pontos do globo e momentos históricos estas infraestruturas foram assumidas como primordiais para o desenvolvimento das sociedades nas quais se inseriam. Num dos primeiros textos sobre o tema e na leitura sobre as condições de emergência do capitalismo na Antiguidade, Max Weber considerava que a construção destes canais impulsionava a burocratização do Estado e o desenvolvimento capitalista. No último século e 
Campos Neutrais - Revista Latino-Americana de Relações Internacionais Vol. 1, No 2, p. 53-72, Maio - Agosto de 2019

meio a opção pela construção destes empreendimentos tem oposto a administração pública a utilizadores, especialistas, populações e movimentos cívicos, sendo contestada em diversos países por reduzir os caudais dos cursos de água emissores, colocar em risco o equilíbrio dos ecossistemas e as vivências tradicionais da água, fomentar o desperdício através de sistemas de irrigação obsoletos e não atender às necessidades de todas as comunidades; suscitando questões que remetem para a temática da justiça social e para o acesso à água como um direito humano.

A temática é particularmente relevante no Nordeste brasileiro, tradicionalmente afetado pela seca, com consequente fome, morte de pessoas e o drama dos refugiados ambientais conhecidos como os retirantes. A região apresenta ciclos de fortes estiagens, secas prolongadas e alto potencial de evaporação da água. O primeiro registro de seca data de 1552 , ano em que o padre Antônio Pires menciona que não chovia em Pernambuco há quatro ou cinco anos. Muitas secas se seguiram, destacando-se pelo seu impacto nas populações as secas de 1777-78, 1877/1888, 1915 e 1932 (KHAN et al., 2005; CAMPOS, 2014).

A possibilidade de transposição das águas do rio São Francisco foi apresentada pela primeira vez, em 1818, no governo de dom João VI, por José Raimundo de Passos Barbosa, primeiro ouvidor do Crato $(\mathrm{CE})$, pretendendo levar água do rio São Francisco ao rio Jaguaribe, no Ceará. O projeto avançou apenas na década de 2000, inaugurando a primeira parte da obra em 2017. Seu histórico associado à variação do clima, e o fato de se tratar da região semiárida mais populosa do mundo e com mais infraestruturas hidráulicas, designadamente reservatórios e adutoras, popularizou a obra e colocou-a no centro da disputa política nacional, reivindicando a sua autoria os ex-presidentes da República Michel Temer e Lula da Silva.

Em nosso artigo analisamos o processo histórico que levou ao avanço das obras da transposição no quadro de resposta à seca no Nordeste brasileiro. O objetivo é reconstruir o histórico do processo para fazer face a diferentes necessidades do semiárido nordestino, solucionando o problema de escassez de água característico da região. Para o efeito, colocando em pauta diferentes abordagens e dimensões do problema, enquadrando a obra no contexto de outros projetos de transposição, para em seguida se destacar avanços e recuos da transposição do São Francisco, assim com posições a favor e divergentes, num processo fortemente marcado pela mitificação da transposição no socorro hídrico ao Nordeste. Dessa forma, recorremos a análise de documentos oficiais e midiáticos, entrevistas, questionários e observação de campo, tendo presente que as duas propostas surgiram historicamente 
Campos Neutrais - Revista Latino-Americana de Relações Internacionais

Vol. 1, No 2, p. 53-72, Maio - Agosto de 2019

praticamente em simultâneo e mobilizam atores sociais e recursos financeiros, humanos e materiais com base em uma proposta de desenvolvimento regional assegurada por meio de grandes infraestruturas hidráulicas.

\section{Metodologia}

$\mathrm{O}$ artigo se insere numa pesquisa mais abrangente, cujo objetivo geral propõe analisar o processo político, técnico e cívico que culminou na decisão de transferir grandes quantidades de massas de água entre bacias hidrográficas como principal medida de combate à escassez de água nas áreas receptoras, com o arranque da transposição das águas do rio São Francisco para as bacias hidrográficas do Nordeste setentrional brasileiro. Na reconstrução do histórico procuramos acompanhar as discussões ocorridas ao longo de mais de duzentos anos, identificando os principais atores envolvidos e suas propostas, dando conta de controvérsias e impasses, seguindo igualmente as transformações institucionais ocorridas no mesmo período e as tendências internacionais de construção de infraestruturas hídricas.

Entre os procedimentos usados neste artigo destacamos, o levantamento de estudos internacionais focados na temática da transposição, pesquisa documental realizada, primeiro, em bibliotecas e arquivos da Universidade Federal do Rio Grande do Norte: NUT Seca/UFRN, Biblioteca Central Zila Mamede e Biblioteca Setorial do Centro de Ciências Humanas, Letras e Artes; assim como online em diversas bibliotecas, entre as quais no espólio da American Libraries sobre o rio São Francisco e da Biblioteca do Senado Federal e o repositório de jornais online disponível na Biblioteca Nacional Digital. Do mesmo modo coletamos notícias da mídia nos jornais dos estados do Ceará, Paraíba, Pernambuco e Rio Grande do Norte referentes aos anos 2017 (SILVA; FERREIRA, 2018) e 2018; fizemos visitas de campo; organizamos debates públicos sobre a temática; realizamos entrevistas semiestruturadas a alguns dos principais intervenientes no processo no Rio Grande do Norte; e nos articulamos em rede com pesquisadores que trabalham a mesma matéria em diversas Universidades do Nordeste.

\section{Transposição das águas do Rio São Francisco}

A transferência de água de rios ou bacias com excedentes para áreas necessitadas tem sido praticada desde que o homem construiu as primeiras grandes cidades, assumindo-se fundamental na organização do território e na estratificação social. Max Weber no debate sobre as origens do capitalismo considerou a racionalização da economia de irrigação da 
Campos Neutrais - Revista Latino-Americana de Relações Internacionais Vol. 1, No 2, p. 53-72, Maio - Agosto de 2019

Antiguidade como crucial para o desenvolvimento das formas burocráticas da administração no Egito, Ásia Menor, Índia e China. Para Weber, a irrigação foi determinante para o desenvolvimento cultural das cidades e do poder do rei, dando "margem à burocracia, à corveia dos súditos e à dependência destes, em todos os aspectos de sua existência, da atividade da burocracia do rei" [ou faraó] (WEBER, 2006, p. 69). No caso da "China, a necessidade de regular os rios e de administrar a irrigação fez nascer uma burocracia real inicialmente apenas ocupada com as obras, mas dando mais tarde origem à burocratização de toda a administração" (WEBER, 2004, p. 444).

Podemos ainda hoje admirar diversos testemunhos do patrimônio herdado dos Romanos, os quais construíram numerosas obras hidráulicas, sendo exímios na construção de aquedutos, mas também barragens e canais, de tal modo que no século III d. C. todas as grandes e médias cidades do Império eram abastecidas por aquedutos. As suas infraestruturas eram usadas para levar água destinada ao consumo humano e para uso agrícola e industrial, conjunto de usos que exigiam tecnologia e elevada capacidade de gestão.

No Peru os Incas possuíam um sistema complexo de irrigação e abastecimento humano. Cusco possuía uma rede de canais protegidos com água oriunda de Urin Chacan e Hanan Chacan. Os canais exerciam uma grande influência na organização e hierarquização dos espaços. Os povos andinos antigos não possuíam apenas conhecimentos práticos de hidrologia e de como utilizar as águas superficiais e subterrâneas, mas também elaboravam uma cosmologia baseada nestes conhecimentos útil para expressar conceitos de etnicidade e unidade pública, em que o conhecimento e controle hidráulico se refletia na estratificação social,na estruturação do território e designadamente no planejamento urbano (ESCOBEDO; ANDRADE, 2013).

A construção de modernas infraestruturas hidráulicas de grandes dimensões ocorreu a partir da segunda metade do séc. XIX, primeiro na Europa e nos Estados Unidos da América, como resposta à transformação em curso nos setores do saneamento básico, produção de energia e desenvolvimento da agricultura irrigada. No que foram construídas barragens e infraestruturas de grandes dimensões para levarem a água de bacias excedentárias para bacias deficitárias, de modo a garantir a transferênciade água e o seu armazenamento (GIL, 2016).

Um dos casos que conhecemos é o da transposição das águas do rio Tejo para o rio Segura, na Península Ibérica, cuja ideia inicial praticamente coincide com o início do debate sobre a transposição das águas do rio São Francisco. A primeira proposta para a transposição das águas do rio Tejo tem antecedentes na Proposta de Lei sobre Caminhos e Canais levada às 
Campos Neutrais - Revista Latino-Americana de Relações Internacionais Vol. 1, $\mathrm{N}^{\mathrm{O}}$ 2, p. 53-72, Maio - Agosto de 2019

Cortes em 1820, mas apenas em 1933 é oficialmente inserida no Plano Nacional de Obras Hidráulicas (CANTERO, 1992).

Nos Estados Unidos da América, em particular na Califórnia, desde a década de 1930 que têm sido transferidas grandes massas de água do rio Colorado. Apesar do sucesso no desenvolvimento da agricultura da região, a infraestrutura tem gerado enorme controvérsia pública motivada pelo aumento de pressão sobre o recurso e sobre a sua qualidade, em que a água destinada ao abastecimento público acaba competindo com a usada na agricultura intensiva produzida na região. A transferência de água na Califórnia gerou um conflito com o México, país no qual deságua o rio e onde a água praticamente não chega ou chega poluída (HANAK el al., 2011).

Na China está em curso o maior projeto de transferência de água da Ásia. A obra é apoiada pelo Banco Mundial, mas muito contestada por associações ambientalistas internacionais, designadamente por implicar no remanejamento de cerca de 330 mil pessoas. O Projeto de Transferência de Água Sul-Norte é a maior transferência de água interbacias, pretende transferir 44,8 bilhões de $\mathrm{m}^{3} /$ ano do Sul a partir do rio Yangtzé para as áreas áridas da bacia do rio Amarelo no Norte do país. O projeto tem três rotas principais: as rotas Oriental e Central, cujas obras se iniciaram na década de 1990; e a rota Oeste com conclusão prevista para 2050 (WANG; LI, 2019).

No Brasil foram transpostos alguns cursos de água, mas o processo que sempre chamou mais a atenção foi o da possibilidade de transposição das águas do rio São Francisco para as bacias hidrográficas do Nordeste setentrional, havendo inicialmente a possibilidade do próprio São Francisco ser reforçado com águas do rio Tocantins (GUERRA, 1981).

A partir do final do século XVII o rio São Francisco adquire importância na geopolítica brasileira com base em sua utilização como estrada fluvial de grande importância na circulação de matérias primas e pessoas, pela fertilidade dos seus vales e da riqueza mineira das serras circundantes. Mas também por seus atributos espirituais, pela sua vazão, que poderia contribuir para a solução do problema da seca no Nordeste setentrional, e pela sua centralidade no território brasileiro, que motivou que José Bonifácio, entre outros, defendesse que ao longo do seu trecho fosse instalada a capital do país, chegando a sugerir o nome de Brasília naquela que viria a ser a cidade de Petrolina (HALFELD, 1860; CARDOSO, 1938; VIDAL, 2015).

A primeira proposta de transposição das águas do São Francisco foi apresentada, em 1818, no governo de dom João VI, por José Raimundo de Passos Barbosa, primeiro ouvidor 
Campos Neutrais - Revista Latino-Americana de Relações Internacionais Vol. 1, $\mathrm{N}^{\mathrm{O}}$ 2, p. 53-72, Maio - Agosto de 2019

do Crato (CE),pretendia levar água do rio São Francisco ao rio Jaguaribe, no Ceará, e permitir a navegabilidade dos canais. Na sequência, o que efetivamente se sabe, é que em 1847, o engenheiro e deputado provincial do Ceará, Marco Antônio de Macedo apresentou nova proposta ao imperador Pedro II, como um meio de combater os problemas gerados pela seca, mas não obteve apoio.

Os projetos iniciais serviram de base à decisão do imperador patrocinar uma expedição ao São Francisco de 1852 a 1854, em que D. Pedro II contratou o Engenheiro Henrique Guilherme Fernando Halfeld para estudar o São Francisco, daí resultando, em 1860, na publicação do "Atlas de Relatório Concernente à Exploração do rio São Francisco desde a Cachoeira da Pirapora até ao Oceano Atlântico", que defendia a retirada das águas próximo à cidade de Cabrobó (PE), afirmando que, em particular a província do Ceará:

que de primeira mão receberá benefício da fácil communicação commercial do mar interior do império e vice versa, e aproveitaria as águas do Rio de S. Francisco para a irrigação das suas terras secas, como meio mais certo e efficaz de providenciar contra o horrível flagelo das grandes secas (HALFELD, 1860, p.36).

Mas a obra não avançou dada a inexistência à época de tecnologia que permitisse tal empreendimento" (SANTANA FILHO, 2007, p.14). Mas também não seria totalmente consensual a sua construção. José Guimarães Duque diz-nos que após viagem em 1827 da Bahia ao Piauí, o marechal de campo Henrique Beaurepaire Rohan escreveu em 1960 uma monografia em que defendia várias medidas de combate à seca e condenava o canal São Francisco-Ceará (DUQUE, 2004, p. 76).

Ainda que não se ligue ao processo de transposição, para conhecer todas as possibilidades de navegabilidade do rio, em 1862 o Imperador D. Pedro II patrocinou outra expedição realizada, na região do Alto São Francisco para definir quais as condições de navegabilidade tanto no rio São Francisco quanto no seu principal afluente, o Rio das Velhas. Convidou para tal o astrônomo, matemático e botânico francês Emmanuel Liais, que em 1865 publicou o livro intitulado Hydrographie du haut San-Francisco et du rio das Velhas (LUNA, 2013).

No Brasil de Oitocentos, à medida que o país conquistou sua autonomia do império português, se esperava um milagre do São Francisco, pela possibilidade do rio contribuir para o povoamento da região, ligando vários estados do interior e do litoral, através de canais de navegação e disponibilidade de água que permitiriam desenvolver várias atividades econômicas. E, de igual modo, por ser uma via de penetração para a conquista dos sertões do 
Campos Neutrais - Revista Latino-Americana de Relações Internacionais Vol. 1, No 2, p. 53-72, Maio - Agosto de 2019

Nordeste e do Leste, igualmente importante na navegação como elemento de ligação entre o Norte e o Sul, recebeu o título de "Rio da unidade nacional", título que reforçava a identidade nacional.

Até ao referido período, na opinião de Vicente Licínio Cardoso (1938), o São Francisco foi um rio sem história. Por um lado, porque as descrições deste foram feitas somente por estrangeiros interessados no estudo de nossa terra, sendo que "que os únicos levantamentos completos executados no São Francisco são os Halfeld, engenheiro allemão contratado por Pedro II, cujas plantas e mappas, valiosíssimos, servem até hoje à navegação precaría daquelle rio magnifico e imponente" (CARDOSO, 1938, p. 36). Por outro lado, pelo fato de não existir história sem sequência, uma vez que pouco se sabia do povoamento e penetração no vale do São Francisco, existindo apenas depoimentos isolados, com dados escassos ou detalhes insignificantes. Mas também, um rio sem história pelo "emmaranhamento desconnexo de dados isolados, sem datas que se superponham ou referências que se completem" (CARDOSO, 1938, p. 39).

Face ao problema das secas que ciclicamente afetam a região, a transposição acabou sendo colocada em períodos de maior contingenciamento, mas por razões técnicas e financeiras acabava sempre por ser abandonada. Foi o que ocorreu após uma Comissão Científica de Exploração, chefiada pelo Barão de Capanema, ser encarregada em 1856 de estudar o problema das secas. De 1859 a 1861, a Comissão Científica de Exploração esteve no Ceará, mas não encontrou nenhum quadro crítico, pois não ocorreu seca nesse período, o que pode ter dificultado seu diagnóstico sobre a seca.

Uma outra Comissão Imperial, do Instituto Politécnico presidido pelo Conde D’Eu, sugeria em 1877, a construção de um canal ligando o rio São Francisco ao Jaguaribe, em concreto para o rio Salgado, mas a ideia foi arquivada e considerada irrealizável (CAMPOS, 2014; SANTANA FILHO, 2007; DUQUE, 2004). Ainda em 1877, o deputado Tristão de Alencar Araripe sugeriu discurso na Câmara a canalização das águas do rio São Francisco para o Ceará. A ideia foi retomada em 1886 pelo engenheiro cearense Tristão Franklin Alencar Lima, que realizou diversas explorações no Rio São Francisco que subsidiaram o mapa que sugeria viabilidade de canais que ligassem o São Francisco aos rios Jaguaribe (Ceará), Piranhas (Paraíba) e Assú (Rio Grande do Norte) (FERREIRA; DANTAS; SIMONINI, 2018; DUQUE, 2004).

Com a criação da Inspetoria de Obras Contra as Secas (IOCS), em 1909, a transposição ganha de novo importância. Os seus técnicos elaboraram em 1912 um esquema 
Campos Neutrais - Revista Latino-Americana de Relações Internacionais Vol. 1, $\mathrm{N}^{\mathrm{O}}$ 2, p. 53-72, Maio - Agosto de 2019

do canal que interligaria os rios São Francisco e Jaguaribe, mas que foi de imediato descartado, pois, segundo Paulo de Brito Guerra:

ficou provado sua inviabilidade, pois o ponto de tomada, que seria o vértice da Cachoeira do Jenipapo, [que] se achava na cota 355 e a cota mínima do divisor de águas estava em 550. O obstáculo a transpor media 195 metros de altura com uma extensão de 350 quilômetros (GUERRA, 1981, p.236).

Apesar dos trabalhos realizados faltava um amplo diagnóstico do rio e das suas potencialidades, de tal modo que a partir de 1913 os mapas "organizados pela lnspectoria de Seccas, então sob a chefia de Aarão Reis, vieran pôr em fóco o disparate de taes projectos, nessa maneira lamentável e inopinada de projectar canaes sem levantamentos geographicos preliminares de referencia" (CARDOSO, 1938, p. 48) Em 1919 uma nova seca levou a que o projeto fosse reconsiderado pela sucessora do IOCS, a Inspetoria Federal de Obras contra as Secas, mas mais uma vez não tece consequências (IFOCS).

O projeto reapareceria no decorrer da grande seca de 1979 a 1983, na gestão de Mário Andreazza à frente do Ministério do Interior, chegando a instalar um canteiro de obras em Rajadas, Petrolina-PE. Apesar do ministro ser conhecido pela audácia de executar grandes obras, entre elas a barragem Armando Ribeiro Gonçalves no Rio Grande do Norte (1983) faltou recursos para concretizar a transposição. A proposta do de Andreazza envolvia os rios São Francisco, Parnaíba e Tocantins, com previsão para ser realizado em 40 anos (RIBEIRO, 2016).

Em 1993, o Ministro da Integração Nacional, Aluísio Alves, propôs a construção de um canal em Cabrobó (Pernambuco) para beneficiar os estados do Ceará e do Rio Grande do Norte. Em 1994, o Ministério da Integração Regional assumiu a apresentação do projeto através da SUDENE, mas um parecer do Tribunal de Contas da União foi contrário à ideia e o projeto acabou arquivado.

Em 1996 o Ministério do Meio Ambiente e da Amazônia Legal se responsabilizou pelo projeto, assumindo a condução do empreendimento a extinta Secretaria Especial de Políticas Regionais, do Ministério do Planejamento e Orçamento. A partir de 1999 o Ministério da Integração Nacional passou à condição de empreendedor do Projeto de Transposição de Águas do Rio São Francisco (SANTANA FILHO, 2007). Porém, a consulta feita em 2001 junto do Banco Internacional para Reconstrução e Desenvolvimento - BIRD no sentido de conceder um empréstimo para a Transposição recebeu resposta negativa, aconselhando o "banco que se fizesse primeiro o aproveitamento das águas já existentes no 
Campos Neutrais - Revista Latino-Americana de Relações Internacionais

Vol. 1, No 2, p. 53-72, Maio - Agosto de 2019

semiárido" (RIBEIRO, 2016, p. 4).

Em 2003, já com o governo de Inácio Lula da Silva na presidência, foi enviado ao Congresso Nacional o plano de investimentos para o período 2004-2007, que contemplava o Projeto de Transposição do Rio São Francisco para a região do Semiárido Nordestino, cujos $700 \mathrm{~km}$ de canais vão ter impacto sobre 45,5 milhões de pessoas. Em 2004 foram apresentados os Estudos de Impacto Ambiental e o Relatório de Impacto Ambiental, com aprovação no ano seguinte pelo Conselho Nacional de Recursos Hídricos do Projeto de Integração do Rio São Francisco com as Bacias Hidrográficas do Nordeste Setentrional.

Com vários momentos de impasse, em março de 2017 foi inaugurada a primeira fase da obra, com a chegada da água do Projeto de Integração do Rio São Francisco a Pernambuco e à Paraíba, inaugurando a maior obra de transposição hídrica do Brasil e da América Latina. Com concretizaçãofaseada e adiada em alguns trechos o objetivo da obra é garantir a segurança hídrica para mais de 390 municípios do Nordeste Setentrional. O empreendimento prevê várias infraestruturas, através de dois eixos - Norte e Leste, abrangendo os estados de Pernambuco, Ceará, Paraíba e Rio Grande do Norte. Dez anos após ter sido iniciada, a água chegou ao Eixo Leste, abastecendo cidades como Sertânia em Pernambuco e Monteiro na Paraíba. Prevendo-se a chegada da água ao Eixo Norte, com ligação ao Ceará, no final de 2018 e ao Rio Grande do Norte apenas no ano seguinte.

\section{Expectativa e controvérsia da transposição}

Não só por sua importância vital para a vida humana e dos ecossistemas, a água sempre esteve presente com grande relevância em todas as culturas, levando o filósofo grego Tales de Mileto a afirmar que a água "é o princípio de todas as coisas" (LÁZARO, 2015, p.7). Foi marcante a sua presença na ocupação do território, no surgimento das cidades e expansão da atividade agrícola. Mas também como elemento definidor da paisagem e da imaginação através de rituais e da expressão artística e base de muitas tradições que configuram práticas e relações sociais (ARROYO; RODRÍGUEZ-MARÍN, 2016).

A água apresenta-se como um dos elementos centrais da dinâmica das relações sociais com características que superam o líquido que sai da torneira, na medida em que é líquido e ativo social na forma como atravessa o nosso quotidiano e intercepta relações entre cidadãos, consumidores, estado e agentes econômicos (ARROJO, 2010; SCHMIDT; PRISTA, 2010). Na perspectiva bachelardiana está presente nas celebrações de vida e morte como substância sonhada e matéria, como elemento que condensa atos e símbolos, e que desperta como 
Campos Neutrais - Revista Latino-Americana de Relações Internacionais Vol. 1, No 2, p. 53-72, Maio - Agosto de 2019

componente sagrada, de veneração e respeito, mas também como motivo de protesto e simultaneamente lugar de contemplação, consolo psíquico e fruição (FERREIRA, 2019).

Tem historicamente motivado disputas e consensos, e é aqui que a água se constitui como elemento através do qual certos grupos buscam controlar o recurso hídrico e manter ou alargar relações de poder nas sociedades em que se inserem, controlando a construção e gestão de grandes obras de irrigação. Segundo Adam French (2016) insistimos na ideia da conquista da natureza, um posicionamento que "tem raízes em crenças da época do Iluminismo sobre os poderes da ciência e da racionalidade para controlar e transformar o mundo tanto natural como social” (FRENCH, 2016, p. 63, tradução nossa) e tem como objetivo o controle da água através do controle da construção megaprojetos de transporte e acumulação de água e da construção de grandes usinas hidrelétricas.

O Projeto de Integração do Rio São Francisco com as Bacias do Nordeste Setentrional (PISF) surge nessa sequência como proposta pós Iluminista de fazer chegar a água ao Ceará e outros estados da região, apresentando a proposta inicial a ideia complementar de construção de canais navegáveis que permitissem criar uma via navegável para navios e que possibilitasse a integração entre o Norte e o Sul do Brasil. Temos assim, que a chegada das águas ao Eixo Leste cumpre sonho dos nordestinos, profetizado pelo padre Cícero, de que o Sertão ia virar mar, mas também o sonho de muitos idealizadores que quiseram consolidar o São Francisco como o rio da integração nacional.

No avanço das preocupações ambientais e climáticas, esse sonho encerra em si um paradoxo, na medida em que é difícil concretizar, ao mesmo tempo, a manutenção desse entendido do São Francisco como "rio da unidade nacional" e um modelo de desenvolvimento regional fortemente ancorado em atividades econômicas muito dependentes do uso da água, tal como é o caso da fruticultura irrigada do Nordeste brasileiro. Esta insistência parece surgir em contramão de iniciativas internacionais no sentido da manutenção dos rios no seu estado natural, quando não da sua renaturalização e sacralização pela lei e pelas comunidades tradicionais. E na sequência, da necessidade de uma nova cultura da água e de um novo entendimento sobre os rios e sua importância também como reservatórios de cultura e de testemunho para as gerações vindouras, propondo para tal infraestruturas com menor pressão sobre os ecossistemas hídricos e promovam equidade no acesso à água pelas comunidades.

Em suma, é necessário um outro entendimento e uma nova cultura da água que leve em consideração que "o rio é um "caminho que anda", não apenas um "recurso hídrico" (MALVEZZI, 2007, p. 37). E que o futuro não deveria ser a transposição, mas a revitalização 
Campos Neutrais - Revista Latino-Americana de Relações Internacionais Vol. 1, No 2, p. 53-72, Maio - Agosto de 2019

do rio, com ampla participação da sociedade civil, envolvendo a população e as comunidades tradicionais, em detrimento da intensificação da captação de água, aumento da contaminação e destruição das matas ciliares, para servir a produção de camarão e agricultura intensiva baseada em elevados consumos de água. Roberto Malvezzi, como também Loreley Garcia e Mayara Meira Wanderley, estão convencidos da irreversibilidade da degradação do rio e da perda de seu significado cultural para os povos que habitam as suas margens. O primeiro considera que o "São Francisco está com a morte anunciada" (MALVEZZI, 2007, p. 38); a segunda receia que nas atividades e na relação das comunidades ribeirinhas a transposição pode significa a condenação do São Francisco ou a constatação de "como um rio-milagre se torna um rio moribundo" (GARCIA; WANDERLEY, 2018, p. 17). Neste ponto, são de saudar os debates recentes no Senado, em particular em audiência pública da Comissão de Desenvolvimento Regional e Turismo a 12 de junho de 2019, e a preocupação não apenas com questões orçamentárias e de conclusão das obras, com previsão de chegada das águas ao Eixo Norte no segundo semestre de 2019, mas igualmente com a recuperação de águas degradadas do rio, o que não será tarefa fácil, pois o o projeto tem sido essencialmente abordado na perspectiva de futuros investimentos que consiga captar.

A transposição foi conseguida na insistência do mito da escassez, que justificou a construção da obra e deu continuidade à indústria da seca posicionando-se como "a última grande obra da indústria da seca e a primeira grande obra do "hidronegócio" destinada a manter velhas lideranças que mantêm o controle da água e território, deixando para abastecimento humano e para o pequeno utilizador uma parte residual no acesso ao recurso (MALVEZZI, 2007, p. 47). Fortalecendo igualmente a indústria da construção e grandes obras públicas (GUIMARÃES JUNIOR, 2010), quando deveria ser um projeto de água para todos capaz de saciar os locais com maior carência do recurso e se efetivar como água como cidadania. A visão de que falamos implica repensar a vocação implícita da água da transposição, que segundo Malvezzi "não foi concebida para saciar a sede de pessoas e animais, mas para alimentar a indústria da irrigação voltada para a exportação" (MALVEZZI, 2007, p. 40).

Estamos falando da desigual distribuição e acesso à água da transposição, mas também como vai ser repartido o benefício pelo uso dessa água. Aí se inserindo igualmente o debate sobre a água como recurso hídrico e como produto natural que pode ser comercializado e disputado no mercado, aumentando a pressão sobre os seus usos, priorizando os usos com maior valor no mercado de exportações ainda que defina como prioridade o abastecimento 
Campos Neutrais - Revista Latino-Americana de Relações Internacionais Vol. 1, No 2, p. 53-72, Maio - Agosto de 2019

humano e dessedentação animal, mas colocando simultaneamente em campo forças com capacidade de influência social e política diferenciada. Temos um empreendimento que ainda não foi concluído e já se posiciona como conflito em potência e assume lugar de agência na forma como o acesso à água será colocado às comunidades e setores produtivos, sendo que a fatura será paga pelo consumidor final de água dos estados quando abre a torneira.

A concretização da transposição não materializa apenas o mito da resposta à seca no semiárido nordestino, é uma proposta de inversão de elementos da própria identidade nordestina, forçando a sua descontinuidade para que a região seja bem sucedida. Entre os traços que podem mudar estão os que identificam o sertanejo como povo que resiste às adversidades secas, apela a Deus e à Natureza, mas também à elite política. É importante pontuar que essa transformação não se inicia agora, e que o rompimento do equilíbrio da sociedade antiga (DUQUE, 2004, p. 22) teve início com a criação da SUDENE, em 1959, planejando e intervindo na expansão econômica do Nordeste, designadamente a expansão da agricultura irrigada, e recebeu novo impulso com a chegada da energia eólica ao Nordeste.

Por outro lado, dada a dimensão da obra e seu lugar estratégico no desenvolvimento do Brasil e na aproximação das regiões com dificuldades em despencar para o desenvolvimento já alcançado por outros estados, a transposição entra igualmente na arena das disputas políticas nacionais na mais alta esfera da nação. A euforia da chegada das águas coloca a obra no campo das disputas políticas e não apenas das opções técnicas, de tal modo que a obra vê reivindicada a sua autoria pelos ex-presidentes da República Michel Temer e Lula da Silva. Em que a ocorrência de uma inauguração oficial e de uma inauguração assumida como popular refletem o desejo de assumir essa paternidade.

Apesar desse campo de disputas e da controvérsia técnica e científica que rodeia o projeto, assinale-se a possível diluição de possíveis conflitos na concretização dessa obra simbólica e da crença nessa narrativa. Ainda assim, não são de menosprezar aspectos alvo de polêmica. $\mathrm{O}$ projeto tem gerado grande expectativa, justificada face aos cenários climáticos para a região e ao histórico das secas, mas também controvérsias públicas, sobretudo pelo impacto nos ecossistemas e nas comunidades. Destacando-se as divergências entre os que defendem o projeto e os que questionam a viabilidade do mesmo, colocando em risco a sustentabilidade.

A transposição é ainda vista de forma preocupante por reduzir a vazão gerando risco de déficit energético por redução de água que permite o funcionamento das usinas hidrelétricas do rio. Não menos importante é a futura utilização das águas da transposição, 
Campos Neutrais - Revista Latino-Americana de Relações Internacionais Vol. 1, $\mathrm{N}^{\mathrm{O}}$ 2, p. 53-72, Maio - Agosto de 2019

cuja prioridade é o abastecimento humano e suprir necessidades de água para animais, garantindo o abastecimento de água de grandes centros urbanos da região e de centenas de pequenas e médias cidades inseridas no semiárido e de áreas do interior do Nordeste. Este reforço hídrico vai gerar renda e desenvolvimento socioeconômico das famílias, permitindo o suprimento de indústrias, empreendimentos turísticos e agrícolas, mas poderá descompensar os estados a jusante do canal da transposição e futuro motivo de conflito (SILVA; FERREIRA, 2018).

Para os opositores a infraestrutura é socialmente injusta, por não levar água para o consumo humano, mas servir o agronegócio, a criação de camarão e a produção de energia (SOARES, 2013); e é tecnicamente errada, pois existe disponibilidade de água na região que poderia satisfazer as necessidades sem obras, e no caso de se concretizar, a água deveria vir do rio Tocantins. Alguns especialistas receiam ainda que esta obra se transforme em mais um "elefante branco", que depois dos enormes investimentos não venha a cumprir a sua função (SUASSUNA, 2016). João Abner Guimarães Junior vai mais longe ao considerar que o projeto inaugura a guerra pela água no Brasil, considerando que a chegada das águas da transposição é apresentada como uma espécie de seguro hídrico que os estados do Ceará, Paraíba, Pernambuco e Rio Grande do Norte irão contratar. Tudo isto sem que se debatam os seus elevados custos, a sua eficiência e se as escolhas foram efetivamente as mais corretas. Em várias intervenções públicas e artigos, Guimarães Junior (2016) tem defendido que o Nordeste precisa não de importação de água, mas sim de proceder a uma ampla reforma hídrica no sentido da eficiência, acompanhada de uma gestão mais democrática e competente da água disponível, considerando serem alternativas suficientes para dispensar a água da transposição, uma obra que necessita avaliar também a sua viabilidade econômica e ambiental.

Nessa discussão entram igualmente questões como os elevados custos da obra e a dificuldade do Rio São Francisco dar resposta tanta demanda, tendo em conta que a sua bacia revela crescentes problemas de poluição e diminuição da vazão. Outro aspecto em discussão diz respeito à aposta quase exclusiva na transposição do rio São Francisco tem impedido a aplicação de outras medidas, com a agravante de captar um importante porcentual dos recursos financeiros e alargar o que conhecíamos como sendo a "indústria da seca" para o lobby da construção de grandes obras e equipamentos (GUIMARÃES, 2016).

Aqui se assume a referência à indústria da seca numa perspectiva alargada, ou seja, não apenas de pipeiros e toda a componente de venda de serviços e pequenos equipamentos, 
Campos Neutrais - Revista Latino-Americana de Relações Internacionais Vol. 1, No 2, p. 53-72, Maio - Agosto de 2019

mas uma indústria da seca com ligações à construção civil e, por conseguinte, à grande infraestrutura hidráulica, de que é exemplo a transposição do rio São Francisco. Por outro lado, apesar de anunciadas as prioridades de abastecimento e da afirmação da obra como um projeto de desenvolvimento regional, o projeto deixa dúvida, podendo contribuir para perpetuar anteriores práticas de irrigação em regiões com uma suposta vocação para plantações de agricultura intensiva, como o Vale do Açu, no Rio Grande do Norte, mantendo um modelo de exportação de elevados quantitativos de água virtual para mercados externos, sem que o benefício fique na região (SOARES, 2013).

No contexto de seca prolongada é bom que a água chegue rápido e não se adie mais a concretização das obras, evitando o colapso de muitos municípios, mas a inauguração da primeira parte da infraestrutura não diminuiu a inquietação. Entre as principais preocupações a destacar as que remetem para a ausência do futuro modelo de gestão do empreendimento, o preço a pagar pela chegada da água, quem vai pagar a fatura e a possibilidade de vazão ser insuficiente para satisfazer a demanda. Por outro lado, os primeiros meses da chegada da água expuseram alguns problemas na obra, sobretudo a elevada evapotranspiração, a rápida deterioração da infraestrutura e os custos adicionais na manutenção. Assim como o atraso na obra, sobretudo da conclusão do Eixo Norte que permitirá fazer chegar a água ao Rio Grande do Norte e Ceará, mas também a segregação de algumas comunidades e municípios.

Além da controvérsia não podemos esquecer igualmente um histórico de "fracassos são crônicos, sucessivos e acumulativos" (RIBEIRO, 2016, p. 5) na conclusão de várias obras da mesma natureza no Nordeste, parte das quais acabando inconclusas e abandonadas, ou com prazos sucessivamente adiados. No Rio Grande do Norte a chegada das águas contará com um atraso de cerca de um ano na conclusão das obras da barragem de Oiticica, município de Jucurutu, cujo objetivo é servir de reservatório à principal barragem do Estado, a barragem Armando Ribeiro Gonçalves. $\mathrm{O}$ atraso ocorreu devido à necessidade de garantir mais recursos financeiros para a sua conclusão, ficando garantidos em julho de 2018 segundo informação da Secretaria de Estado do Meio Ambiente e Recursos Hídricos do Rio Grande do Norte.

Não menos importante são as imagens de desalento das comunidades, uma vez que a chegada das águas aos canais da transposição não são garantia de acesso à água, designadamente por falta de planejamento e infraestrutura. Por outro lado, o rompimento de canais e a elevada evapotranspiração têm ganho enorme visibilidade e são motivo de preocupação (SILVA; FERREIRA, 2018). Ao que se acrescenta novo adiamento na chegada das águas ao Eixo Norte, o mesmo é dizer ao Ceará e Rio Grande do Norte. É igualmente uma 
Campos Neutrais - Revista Latino-Americana de Relações Internacionais

Vol. 1, $\mathrm{N}^{\mathrm{O}}$ 2, p. 53-72, Maio - Agosto de 2019

incógnita o modelo de gestão a adotar e a quem cabe o pagamento da água, perspectivando-se novos focos de conflito ao ser cobrado o pagamento da transposição ao consumidor final da água, constituindo uma sobrecarga nos orçamentos familiares num contexto particularmente sensível decorrente do momento de crise.

Por último, importa olhar para o rio São Francisco e para outros focos de tensão social, em particular os resultantes da degradação da cabeceira e do seu curso até aos canais da transposição. Em causa está sobretudo a perda de biodiversidade e de vegetação em geral, que seca as nascentes, assim como a contaminação das águas e o uso intensivo para a agricultura. A jusante dos canais da transposição até à foz é enorme a preocupação dos estados, pela mais que provável perda de vazão e concentração de poluição, o que tem impacto na quantidade de água disponível.

\section{Considerações finais}

O Projeto de Integração do Rio São Francisco com Bacias Hidrográficas do Nordeste Setentrional é uma obra simultaneamente controversa e encarada como a solução para a escassez de água no semiárido brasileiro, ciclicamente afetado por longos períodos de seca e com um regime de chuva torrencial concentrada em pouco mais de três meses. A obra da esperança é também controversa, pela sua dimensão, custo envolvido e opções tomadas, assim como pela possibilidade de se submeter à articulação do lobby político-empresarial e legitimar novas hierarquias sobre formas tradicionais de poder e de influência político social.

A mudança climática e sobretudo a necessidade do projeto se fundar como proposta de desenvolvimento da região vem trazer novos desafios. Importa lembrar que a convivência com o semiárido recorre a várias ações para mitigar e adaptar a região à escassez de água, mitigando igualmente o efeito sobre as populações através de programas assistencialistas. A transposição se apresenta como a solução para os problemas de escassez, mas não poderá abdicar das ações em curso. Espera-se é que venha a exigir menor utilização de carros-pipa e forneça água às populações num quadro de maior regularidade e qualidade. Porém, não será uma opção milagrosa e terá elevados custos para os estados aderentes. Como medida para levar água às populações carece de um planejamento mais abrangente, estratégico e multissetorial, de outra forma mantém a velha fórmula do abastecimento para consumo e para satisfação das necessidades de água da agricultura intensiva.

Quanto ao abastecimento das populações sertanejas só o futuro dirá, o que de momento preocupa é que a rota da água não passará necessariamente nas regiões mais 
Campos Neutrais - Revista Latino-Americana de Relações Internacionais Vol. 1, $\mathrm{N}^{\mathrm{O}}$ 2, p. 53-72, Maio - Agosto de 2019

necessitadas, passando a quilômetros para abastecer cidades e territórios menos necessitados, mas que necessitam da água para darem continuidade à atividade agrícola intensiva. Certos que o debate está apenas no início, procuramos em nosso artigo deixar uma reflexão sobre aspectos transversais consideráveis.

A recuperação do rio em todo seu percurso necessita ser colocada na agenda de prioridades, de contrário, a transposição não vira apenas elefante branco, poderá transformarse em um dos maiores problemas de degradação ambiental do Brasil. O São Francisco necessita ser transformado em rio vivo, investindo em saneamento para se atingir a pureza das águas e fruição das comunidades e visitantes. Cuidar do rio e dos ecossistemas ribeirinhos é valorizar a sua história, o encanto das águas e todo seu potencial de valorização econômica.

\section{Bibliografia}

AGUDO, Pedro Arrojo. Crisis global del agua: valores y derechos en juego. Cristianisme i Justícia, 2010.

ALMEIDA, José Américo de. As secas do Nordeste. Exposição feita na Câmara dos Deputados em 10-11-1953. Debates e Repercussão. Serviço de Documentação Ministério da Viação e Obras Públicas. 1953.

ARROYO, Jorge Fernández; RODRÍGUEZ-MARÍN, Fátima. Los procesos de enseñanzaaprendizaje relacionados con el agua en el marco de las hipótesis de transición. Revista Eureka sobre Enseñanza y Divulgación de las Ciencias, v. 14, n. 1, p. 227-243, 2016. Disponível em: https://revistas.uca.es/index.php/eureka/article/view/3012/3035. Acesso em: 12 de junho de 2019.

CAMPOS, CAMPOS, José Nilson B Secas e políticas públicas no semiárido: ideias, pensadores e períodos. Estudos Avançados, v. 28, n. 82, p. 65-88, 2014.

CANTERO, Nicolás Ortega. El plan nacional de obras hidráulicas. In Antônio Gil Olcina\& Alfredo Morales Gil (Coord.). Hitos Históricos de obras de los regadíos españoles. Madrid: Ministério da Agricultura, Alimentación y Medio Ambiente, p.335-364, 1992.

CARDOSO, Vicente Licínio. À margem da história do Brasil. Livro pósthumo. Brasiliana, Vol. 13, São Paulo, Rio De Janeiro, Recife, Porto Alegre: Companhia Editora Nacional, 1938. Disponível em https://bdor.sibi.ufrj.br/bitstream/doc/91/1/13\%20PDF\%20-\%20OCR\%20RED.pdf. Acesso em: 5 de junho de 2019.

CASTRO, César Nunes de. Transposição do rio São Francisco: Análise de oportunidade do projeto, Texto para Discussão, $N^{\circ}$. 1577, Brasília: Instituto de Pesquisa Econômica Aplicada (IPEA), 2011.

DUQUE, José Guimarães. Perspectivas Nordestinas. Fortaleza: Banco do Nordeste do Brasil, 2004, $2^{\text {a }}$ ed. 
Campos Neutrais - Revista Latino-Americana de Relações Internacionais Vol. 1, $\mathrm{N}^{\mathrm{O}}$ 2, p. 53-72, Maio - Agosto de 2019

ESCOBEDO, Melissa A.; ANDRADE, Liza M. S. de. Técnicas Hidráulicas Incas: estudo de soluções para amenizar as consequências das mudanças climáticas no Peru. Anais do Encontro Latinoamericano de Edificações e Comunidades sustentáveis. ELECS, Curitiba. 2013. Disponível em: http://www.elecs2013.ufpr.br/Anais/comunidades/77-158-1RV.pdf. Acesso em: 26 de junho de 2018.

FERREIRA, Ângela Lúcia; DANTAS, George Alexandre Ferreira; SIMONINI, Yuri. Contra as secas. Técnica, Natureza e Território. Rio de Janeiro: Letra Capital: INCT/Observatório das Metrópoles, 2018.

FERREIRA, José Gomes. Desafios para uma nova cultura da água. In Ferrão, João et al. (Coord.). Reflexões sobre Ambiente, Território e Sociedade. Três Anos do Blogue ATS. Lisboa: OBSERVA - Instituto de Ciências Sociais da Universidade de Lisboa, 2019, p.196199.

FRENCH, Adam. ¿ Una nueva cultura de agua?: inercia institucional y gestión tecnocrática de los recursos hídricos en el Perú. Anthropologica, v. 34, n. 37, p. 61-86, 2016. Disponível em: http://www.scielo.org.pe/pdf/anthro/v34n37/a04v34n37.pdf. Acesso em:12 de junho de 2019.

GARCIA, Lorelei; WANDERLEY, Mayara Meira. Das águas encantadas às águas da ilusão. $O$ caso da Transposição do Rio São Francisco. Curitiba: BrazilPublishing, 2018.

GIL, Fermín Villarroya. Los conflictos sobre el trasvase del Ebro y del Tajo. M+ A. Revista Electrónica de Medioambiente, n. 2, p. 56-72, 2016. Disponível em: https://www.ucm.es/data/cont/media/www/pag-41377/2006\%202\%20villarroya.pdf. Acesso em: 15 de junho de 2018 .

GUIMARÃES JUNIOR, João Abner. O destino dos canais da transposição do rio são Francisco. EcoDebate. 06/04/2010. Disponível em:

https://www.ecodebate.com.br/2010/04/06/o-destino-dos-canais-da-transposicao-do-rio-saofrancisco-artigo-de-joao-abner-guimaraes-jr/. Acesso em: 12 de junho de 2019.

GUIMARÃES JUNIOR, João Abner. Reforma hídrica do Nordeste como alternativa à transposição do rio São Francisco. Cadernos do CEAS: Revista crítica de humanidades, $\mathrm{N}^{\circ}$ 227, pág. 80-88, 2016. Disponível em:

https://cadernosdoceas.ucsal.br/index.php/cadernosdoceas/article/download/135/115. Acesso em: 23 de março de 2018.

HALFELD, Henrique Guilherme Fernando. Atlas e relatorio concernente a exploração do Rio de S. Francisco desde a Cachoeira da Pirapora até ao Oceano Atlantico. Rio de Janeiro: Typ. Moderna de Georges Bertrand, 1860. Disponível em:

http://www2.senado.leg.br/bdsf/item/id/185636. Acessoem: 2 de maio de 2019.

HANAK, Ellen; LUND, Jay; DINAR, Ariel; GRAY, Brian.; HOWITT, Richard, MOUNT, Jeffrey; MOYLE, Peter; THOMPSON, Barton "Buzz". Managing California's Water:

From Conflict to Reconciliation. San Francisco: Public Policy Institute of California, 2011. Disponível em: https://www.ppic.org/content/pubs/report/R_211EHR.pdf. Acesso em: 2 de maio de 2019. 
Campos Neutrais - Revista Latino-Americana de Relações Internacionais Vol. 1, No 2, p. 53-72, Maio - Agosto de 2019

KHAN, AhmadSaeed; CRUZ, José Alfredo Nicodemos da; SILVA, Lucia Maria Ramos; LIMA, Patrícia Verônica Pinheiro Sales. Efeito da seca sobre a produção, a renda e o emprego agrícola na microrregião geográfica de Brejo Santo e no estado do Ceará. Revista Econômica do Nordeste, vol. 36, n. 2, p. 242-262, 2005.

LÁZARO, Ruth Pérez. La Nueva Cultura del Agua, el camino hacia una gestión sostenible. Causas e impactos de la crisis global del agua. Cuadernos de Trabajo Hegoa, n. 68, 2016. Disponível em: http://www.ehu.eus/ojs/index.php/hegoa/article/viewFile/15672/13586.

Acesso em: 12 de junho de 2019.

MALVEZZI, Roberto. Semi-árido - uma visão holística. Brasília: Confea. Pensar Brasil, 2007. Disponível em https://robertomalvezzi.com.br/wpcontent/uploads/2016/06/phpCDo4mz.pdf. Acesso em: 12 de junho de 2019.

RIBEIRO, Manoel Bomfim. Transposição. Uma análise cartesiana. Cadernos do CEAS: Revista crítica de humanidades, n. 228, p. 67-73, 2016.

SALCEDO, RosioFernandezBaca; OLIVEIRA, Lívia de. O centro histórico de Cusco-Peru no passado. Anais do Seminário de História da Cidade e do Urbanismo, vol. 4, n. 2, p. 306314, 2012.

SANTANA FILHO, João Reis. Projeto São Francisco: garantia hídrica como elemento dinamizador do semi-árido nordestino. Inclusão Social, n. 2, 2008. Disponível em: http://revista.ibict.br/inclusao/article/view/1598. Acesso em: 14 de agosto de 2018.

SCHMIDT, Luísa; PRISTA, Pedro. Água, o líquido social. CCDR-Centro. À beira da água. Coimbra: Comissão de Coordenação e Desenvolvimento Regional do Centro, p. 6-39, 2010.

SILVA, Paula Vivian Oliveira da; FERREIRA, José Gomes. Transposição das águas do rio São Francisco: cobertura midiática nos jornais Diário do Sertão e Tribuna do Norte. Anais CONADIS. I Congresso Nacional da Diversidade do Semiárido. Campina Grande: Realize Eventos \& Editora. V. 1, 2018. Disponível em: https://editorarealize.com.br/revistas/conadis/trabalhos/TRABALHO_EV116_MD1_SA22_I D84_30112018151200.pdf. Acesso em: 11 de junho de 2019.

SOARES, Edmilson. Seca no Nordeste e a transposição do rio São Francisco. Revista Geografias, vol. 9, n. 2, p.75-86, 2013. Disponível em: https://igc.ufmg.br/portaldeperiodicos/index.php/geografias/article/viewFile/593/463. Acesso em: 22 de agosto de 2018.

SUASSUNA, João. As águas do Nordeste e o projeto de transposição do rio São Francisco.Cadernos do CEAS: Revista crítica de humanidades, n. 227, p. 26-36, 2016. Disponível em: http://www.journals.ufrpe.br/index.php/apca/article/download/71/67. Acesso em: 21 de maio de 2018.

VIDAL, Laurent. O São Francisco, um rio de muitas esperas. Confins. Revue francobrésilienne de géographie/Revista franco-brasilera de geografia, n. 23, 2015. Disponível em: https://journals.openedition.org/confins/10100. Acesso em: 6 de junho de 2019.

WANG, Mark; LI, Chen. An institutional analysis of China's South-to-North water diversion. ThesisEleven, v. 150, n. 1, 2019, p. 68-80. Disponível em: 
Campos Neutrais - Revista Latino-Americana de Relações Internacionais Vol. 1, No 2, p. 53-72, Maio - Agosto de 2019

https://journals.sagepub.com/doi/pdf/10.1177/0725513618822419. Acesso em: 2 de maio de 2019.

WEBER, Max. A gênese do capitalismo moderno. São Paulo: Editora Ática, 2006.

WEBER, Max. Economia e sociedade. Fundamentos da sociologia compreensiva, vol. 2. Brasília: Editora Universidade de Brasília; São Paulo: Imprensa Oficial do Estado de São Paulo, 2004. 